\title{
Keanekaragaman Vegetasi Mangrove di Pantai Tanamon Sulawesi Utara (Diversity of Mangrove Vegetation in Tanamon Beach North Sulawesi)
}

\author{
Eka Yuningsih ${ }^{1)^{*}}$, Herni E.I Simbala ${ }^{2)}$, Febby E.F Kandou ${ }^{2)}$ \& Saroyo ${ }^{2)}$ \\ ${ }^{1)}$ Alumni Jurusan Biologi Fakultas MIPA Universitas Sam Ratulangi Manado \\ 2) Jurusan Biologi Fakultas MIPA Universitas Sam Ratulangi Manado \\ *Email korespondensi: ekayuningsih_mulya@yahoo.com
}

Diterima 22 Juli 2013, diterima untuk dipublikasikan 12 Agustus 2013

\begin{abstract}
Abstrak
Studi keanekaragaman dan indeks nilai penting telah dilakukan pada vegetasi mangrove di kawasan Pantai Tanamon dengan menggunakan metode purposive sampling. Ukuran petak ditentukan dengan menggunakan kategori pengelompokan semai $\left(2 \times 2 \mathrm{~m}^{2}\right)$, pancang $\left(5 \times 5 \mathrm{~m}^{2}\right)$, tiang $\left(10 \times 10 \mathrm{~m}^{2}\right)$ dan pohon $\left(20 \times 20 \mathrm{~m}^{2}\right)$. Keanekaragaman vegetasi mangrove di Pantai Tanamon ditentukan dengan menggunakan rumus indeks keanekaragaman Shannon-Wienner. Hasil penelitian menunjukkan bahwa keanekaragaman vegetasi tergolong sedang dengan nilai indeks 1,412. Di kawasan Pantai Tanamon terdapat 6 jenis mangrove yaitu Avicennia marina, Sonneratia alba, Xylocarpus granatum, Rhizophora apiculata, Nypa fruticans dan Terminalia catappa. Indeks nilai penting tertinggi pada pada X. granatum untuk kategori semai (72,977\%), A. marina untuk kategori pancang (80,357 \%), A. marina untuk kategori tiang $(91,623 \%)$ dan S. alba untuk kategori pohon (142,191\%).

Kata kunci: mangrove, keanekaragaman, PantaiTanamon
\end{abstract}

\begin{abstract}
A study on the diversity and the importance value index of mangrove vegetation in the area of Tanamon Beach was conducted using purposive sampling method. Plot size was determined using classification category of seedling $\left(2 \times 2 \mathrm{~m}^{2}\right)$, stake $\left(5 \times 5 \mathrm{~m}^{2}\right)$, pole $\left(10 \times 10 \mathrm{~m}^{2}\right)$ and tree $\left(20 \times 20 \mathrm{~m}^{2}\right)$. The diversity of mangrove vegetation in the Tanamon Beach was determined using the diversity index formula of Shannon-Wienner. The results indicated that vegetation diversity was medium and the index value was 1.412. The mangrove vegetation consisted of 6 species, i.e. Avicennia marina, Sonneratia alba, Xylocarpus granatum, Rhizophora apiculata, Nypa fruticans and Terminalia catappa. The highest importance-value-index was in the $\mathrm{X}$. granatum seedling (72.977\%), A. marina stake (80.357\%), A. marina pole (91.623\%) and S. alba tree $(142.191 \%)$.

Keywords: mangrove, diversity, Tanamon Beach
\end{abstract}

\section{PENDAHULUAN}

Mangrove merupakan suatu tipe vegetasi yang khas terdapat di daerah pantai tropis dan umumnya tumbuh subur di daerah pantai dekat muara sungai dan pantai yang terlindung dari kekuatan ombak (Nursal et al., 2005). Fungsi mangrove secara ekologis yaitu sebagai tempat pemijahan (spawning), pengasuhan (nursery) dan tempat mencari makanan (feeding) bagi biota tertentu (Onrizal et al., 2008).

Luas total hutan mangrove di seluruh Sulawesi Utara pada tahun 1982 yang tersebar di sejumlah kabupaten daerah tingkat II sekitar 
27.300 ha (Kaunang dan Kimbal, 2009). Kawasan mangrove di Pantai Tanamon adalah salah satu kawasan yang terletak di Sulawesi Utara. Luas hutan mangrove di Pantai Tanamon adalah sekitar 5 hektar. Hutan tersebut terbentuk secara alami dan merupakan kawasan konsrvasi lokal sejak tahun 2008.

Studi vegetasi belum pernah dilakukan di kawasan Tanamon. Hal ini mengakibatkan belum adanya data mengenai keanekaragaman vegetasi mangrove di kawasan Pantai Tanamon. Berdasarkan latar belakang tersebut maka perlu dilakukan penelitian mengenai keanekaragaman vegetasi mangrove di kawasan Pantai Tanamon sehingga dapat mengkaji keanekaragaman dan indeks nilai penting vegetasi mangrove di Pantai
Tanamon, Kecamatan Sinonsayang, Sulawesi Utara.

\section{METODE}

Penelitian ini dilaksanakan dengan mengambil lokasi kawasan Pantai Tanamon, Kecamatan Sinonsayang, Sulawesi Utara pada Maret-Mei 2013 dengan batas koordinat $01^{\circ} 01^{\prime} 37.4-01^{\circ} 01^{\prime} 59.8$ LS dan $124^{\circ} 18^{\prime} 17.3-124^{\circ} 18^{\prime} 30.1$ BT di bagian pantai, $01^{\circ} 01^{\prime} 39.9$ $01^{\circ} 01^{\prime} 57.7 \mathrm{LS}$ dan $124^{\circ} 18^{\prime} 21.9$ $124^{\circ} 18^{\prime} 32.7$ BT di bagian darat. Alat yang digunakan dalam penelitian ini adalah tali rafia, patok, $\mathrm{pH}$ meter, salinometer, hygrometer, GPS (Global Positioning System) dan kamera. Alat dan bahan yang digunakan dalam pembuatan herbarium yaitu alkohol $70 \%$, kertas koran, sasak, tali pengikat, lem dan karton.

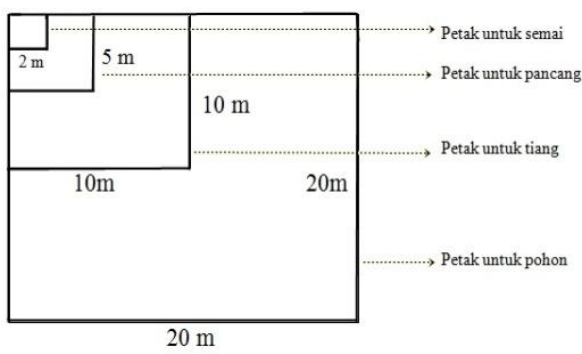

Gambar 1. Penentuan ukuran plot pengambilan data untuk tingkat semai $(2 \mathrm{~m} \times 2$ $\mathrm{m})$, pancang $(5 \mathrm{~m} \times 5 \mathrm{~m})$, tiang $(10 \mathrm{~m} \times 10 \mathrm{~m})$ dan pohon $(20 \mathrm{~m} \times 20$ m) (Fachrul, 2006)

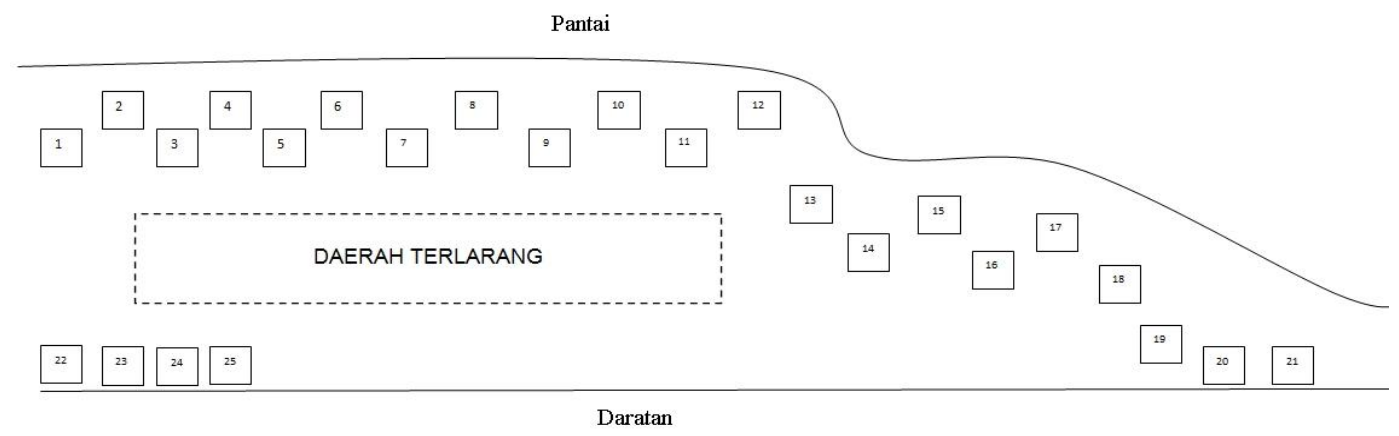

Gambar 2. Sebaran petak pada lokasi penelitian 
Metode yang digunakan di lapangan adalah metode purposive sampling yaitu teknik yang digunakan apabila sampel yang akan diambil memiliki pertimbangan tertentu. Peneliti menggunakan metode tersebut berdasarkan kehadiran suatu jenis dan terdapatnya lokasi yang dilarang untuk dilalui. Ukuran petak ditentukan dengan menggunakan kategori pengelompokan yang disarankan oleh Wyatt dan Smith (1963) dalam Simbala (2007) yaitu untuk kategori semai $2 \times 2 \mathrm{~m}^{2}$, pancang $5 \times 5 \mathrm{~m}^{2}$, tiang $10 \times 10 \mathrm{~m}^{2}$ dan pohon $20 \times 20 \mathrm{~m}^{2}$. Masing-masing kategori berjumlah 25 petak dengan luas luas kawasan sekitar 5 hektar. Penentuan ukuran petak dapat dilihat pada Gambar 1, sedangkan sebaran petak pada lokasi penelitian dapat dilihat pada Gambar 2.

Parameter lingkungan diukur pada setiap petak. Semua vegetasi mangrove yang terdapat dalam petak didata meliputi nama spesies, jumlah individu tiap jenis, dan diameter batang setinggi dada atau diameter at breast height (dbh) untuk kategori tiang dan pohon. Mangrove pada kategori semai dan pancang didata nama spesies dan jumlah individu masing-masing spesies (Istomo dan Kusmana, 1997). Jenis tumbuhan yang belum diidentifikasi di lapangan, diambil spesimennya, difoto, kemudian diidentifikasi dengan menggunakan buku identifikasi (Noor et al., (1999). Sampel tumbuhan yang sudah diambil dibuat herbarium. Data vegetasi tersebut kemudian dianalisis.

$$
\mathrm{H}^{\prime}=-\sum_{i=1}^{S} \mathrm{p}_{\mathrm{i}} \ln \left(\mathrm{p}_{\mathrm{i}}\right)
$$

dimana $p_{i}=\frac{n_{i}}{N}$

Keterangan:

$\mathrm{H}^{\prime}=$ Indeks Keanekaragaman Shannon-Wienner

$\mathrm{n}_{\mathrm{i}}=$ Jumlah individu suatu jenis

$\mathrm{N}=$ Jumlah total individu jenis

$\mathrm{p}_{\mathrm{i}}=$ Proporsi jumlah individu suatu jenis ke-i

$\mathrm{S}=$ Jumlah jenis
Analisis Data

Indeks Keanekaragaman (H')

Indeks keanekaragaman

Shannon-Wienner diperoleh dengan parameter kekayaan jenis dan proporsi kelimpahan masing-masing jenis pada suatu habitat (Krebs, 1972). Kekayaan jenis adalah jumlah jenis dari suatu komunitas, sedangkan kelimpahan adalah jumlah individu dalam suatu jenis (Genisa, 2006). Rumus yang digunakan adalah persamaan (1) menurut Krebs (1972).

Fachrul

mendefinisikan besarnya indeks keanekaragaman jenis yaitu apabila nilai $\mathrm{H}^{\prime}>3$ maka keanekaragaman jenis adalah tinggi atau melimpah, apabila nilai $\mathrm{H}^{\prime} 1 \leq \mathrm{H}^{\prime} \leq 3$ maka keanekaragaman jenis adalah sedang dan apabila nilai $\mathrm{H}^{\prime}<1$ maka keanekaragaman spesies adalah sedikit atau rendah.

\section{Indeks Nilai Penting (INP)}

Indeks nilai penting (importance value index) adalah parameter kuantitatif yang dipakai untuk menyatakan tingkat penguasaan suatu jenis terhadap jenis-jenis lain dalam suatu komunitas (Himmah et al., 2010). INP juga dapat digunakan untuk memberikan gambaran tentang peranan suatu jenis mangrove dalam ekosistem (Romadhon, 2008). Rumus INP menurut Istomo dan Kusmana (1997) yaitu:
a. Kategori semai dan pancang yaitu: INP $=\mathrm{Kr}+\mathrm{Fr}$
b. Kategori tiang dan pohon yaitu: $\mathrm{INP}=\mathrm{Kr}+\mathrm{Fr}+\mathrm{Dr}$ 
Kerapatan merupakan jumlah tegakan individu suatu jenis dalam suatu area (Suzana et al., 2011). Frekuensi merupakan peluang suatu jenis ditemukan dalam titik contoh yang diamati, sedangkan dominansi merupakan besarnya luasan populasi pada suatu area cuplikan (Syah et al. 2007). Persamaan (2) digunakan untuk mengetahui nilai tersebut (Fachrul 2006).

\section{HASIL DAN PEMBAHASAN \\ Deskripsi Lokasi Penelitian}

Lokasi penelitian terletak di

Pantai Tanamon, Desa Tanamon, Kecamatan Sinonsayang,

Kabupaten Minahasa Selatan Sulawesi Utara. Tanamon terletak di bagian Barat Kecamatan Sinonsayang. Bagian Utara Desa Tanamon berbatasan dengan Poigar, bagian selatan berbatasan dengan Desa Aergale, bagian Timur berbatasan dengan Desa Tondey dan sebelah Barat berbatasan dengan Laut Sulawesi.
Parameter

lingkungan meliputu temperatur berkisar antara $27{ }^{\circ} \mathrm{C}-28{ }^{\circ} \mathrm{C}$ dan $\mathrm{pH}$ berkisar antara 6-7. Salinitas pada lokasi penelitian berkisar antara $24 \%$ $29 \%$. Lokasi dengan salinitas yang paling rendah umumnya didominasi oleh $N$. fruticans dan $T$. catappa. Secara visual substrat pada lokasi umumnya yaitu pasir berlumpur yang didominasi oleh jenis $A$. marina. Hal ini sesuai pernyataan Onrizal et al. (2009) yang menyatakan bahwa jenis $A$. marina dapat tumbuh baik pada substrat pasir berlumpur.

$$
\text { Jenis mangrove yang }
$$

ditemukan terdapat 6 jenis mangrove dari 368 individu. Jenis mangrove tersebut yaitu Avicennia marina sebanyak 141 individu, Xylocarpus granatum 110 individu, Sonneratia alba 95 individu, Terminalia catappa 20 individu, Rhizophora apiculata 13 individu dan Nypa fruticans 7 individu.

$$
\begin{aligned}
& \text { Kerapatan }(\mathrm{K})=\frac{\sum \text { individu jenis } i}{\sum \text { luas petak }} \\
& \text { Kerapatan relatif }(\mathrm{Kr})=\frac{\text { Kerapatan spesies } i}{\sum \text { Kerapatan seluru } \mathrm{h} \text { jenis }} \times 100 \% \\
& \text { Frekuensi }(\mathrm{F})=\frac{\sum \text { petak kehadiran jenis } i}{\sum \text { petak }} \\
& \text { Frekuensi relatif }(\mathrm{Fr})=\frac{\sum \text { Frekuensijenis } i}{\sum \text { frekuensi seluru } \mathrm{h} \text { jenis }} \times 100 \% \\
& \text { Dominansi }(\mathrm{D})=\frac{\sum \text { BAjenis } i}{\sum \text { petak } / \text { semua unit sampel }} \\
& \text { Dominansi relatif }(\mathrm{Dr})=\frac{\sum \text { BA jenis } i}{\sum B \text { seluru } \mathrm{h} \text { jenis }} \times 100 \%
\end{aligned}
$$




\section{Analisis Vegetasi Mangrove Indeks Keanekaragaman (H')}

Tabel 1. Indeks keanekaragaman $\left(\mathrm{H}^{\prime}\right)$ mangrove di Pantai Tanamon

\begin{tabular}{|c|c|c|c|c|c|}
\hline No & Jenis & Kelimpahan & pi & pi In pi & pi In pi \\
\hline 1 & A. marina & 141 & 0,365 & $-1,008$ & $-0,368$ \\
\hline 2 & $X$. granatum & 110 & 0,285 & $-1,255$ & $-0,358$ \\
\hline 3 & S. alba & 95 & 0,246 & $-1,402$ & $-0,345$ \\
\hline 4 & T. catappa & 20 & 0,052 & $-2,957$ & $-0,154$ \\
\hline 5 & R. apiculata & 13 & 0,034 & $-3,381$ & $-0,115$ \\
\hline 6 & N. fruticans & 7 & 0,018 & $-4,017$ & $-0,072$ \\
\hline & jumlah & 386 & 1 & $-14,02$ & $-1,412$ \\
\hline \multicolumn{5}{|c|}{ Indeks Keanekaragaman ( $\left.\mathrm{H}^{\prime}\right)$} & 1,412 \\
\hline
\end{tabular}

Tabel 1 menunjukkan bahwa pada kawasan Pantai Tanamon terdapat 6 jenis mangrove dengan jumlah individu yang didapat yaitu 386 individu. Nilai indeks keanekaragaman Shannon-Wienner vegetasi mangrove di Pantai Tanamon yaitu 1,412. Apabila menggunakan kriteria Fachrul (2006) maka di Pantai Tanamon memiliki keanekaragaman mangrove dalam tingkat sedang.

\section{Indeks Nilai Penting (INP)}

INP tertinggi pada kategori semai yaitu pada jenis $X$. granatum sebesar $72,977 \%$. INP tertinggi pada kategori pancang yaitu $A$. marina sebesar $80,357 \%$. INP tertinggi pada kategori tiang yaitu pada jenis $A$. marina sebesar 91,623 $\%$, sedangkan untuk kategori pohon, INP tertinggi yaitu pada jenis $S$. alba sebesar 142,191 \%. Hal ini menunjukkan bahwa pada jenis $X$. granatum, A. marina dan S. alba merupakan jenis yang paling mendominasi di kawasan Pantai Tanamon.

Nilai kerapatan relatif tertinggi pada kategori semai yaitu pada $X$. granatum sebesar 51,765 $\%$. Nilai kerapatan relatif tertinggi pada kategori pancang yaitu pada $X$. granatum sebesar 45,833 \%. Nilai kerapatan relatif tertinggi pada kategori tiang yaitu pada $A$. marina sebesar 36,842 \%, sedangkan nilai kerapatan relatif tertinggi pada kategori pohon yaitu pada $A$. marina yaitu sebesar $48,718 \%$. Hal ini menunjukkan bahwa jenis $X$. granatum dan $A$. marina mempunyai jumlah individu yang paling banyak dan memiliki kemampuan untuk beradaptasi dengan baik terhadap kondisi lingkungan.

Nilai frekuensi relatif tertinggi pada kategori semai yaitu pada $A$. marina sebesar $27,273 \%$. Nilai frekuensi relatif tertinggi pada kategori pancang yaitu $A$. marina yaitu sebesar $42,857 \%$. Nilai frekuensi relatif tertinggi pada kategori tiang yaitu $S$. alba sebesar $35,714 \%$, sedangkan nilai frekuensi relatif tertinggi pada kategori pohon yaitu pada $S$. alba sebesar 45,946 $\%$. Hal ini menunjukkan bahwa jenis A. marina dan $S$. alba merupakan jenis yang memiliki kemampuan adaptasi yang baik terhadap kondisi lingkungan. Hal tersebut sesuai dengan pernyataan Simbala (2007) bahwa jenis yang memiliki nilai frekuensi dan nilai kerapatan tertinggi merupakan kategori jenis yang memiliki kemampuan adaptasi yang baik terhadap kondisi lingkungan.

Nilai dominansi relatif tertinggi pada kategori pancang yaitu T. catappa sebesar $25,706 \%$. Nilai dominansi relatif tertinggi pada 
Tabel 2. Indeks nilai penting vegetasi mangrove kategori semai, pancang, tiang dan pohon.

\begin{tabular}{|c|c|c|c|c|c|c|c|c|c|}
\hline \multicolumn{10}{|c|}{ Semai } \\
\hline No & Jenis & $\mathbf{n}$ & $\begin{array}{c}\mathbf{K} \\
\text { (individu/m²) }\end{array}$ & $\begin{array}{l}\text { KR } \\
(\%)\end{array}$ & $\mathbf{F}$ & FR (\%) & $\begin{array}{c}\mathbf{D} \\
\left(\mathrm{cm}^{2} / \mathrm{m}^{2}\right)\end{array}$ & DR (\%) & $\begin{array}{l}\text { 1NP } \\
(\%)\end{array}$ \\
\hline 1 & X. granatum & 44 & 0,440 & 51,765 & 0,280 & 21,212 & - & - & 72,977 \\
\hline 2 & A. marina & 16 & 0,160 & 18,824 & 0,360 & 27,273 & - & - & 46,097 \\
\hline 3 & S. alba & 9 & 0,090 & 10,588 & 0,240 & 18,182 & - & - & 28,770 \\
\hline 4 & N. fruticans & 7 & 0,070 & 8,235 & 0,120 & 9,091 & - & - & 17,326 \\
\hline 5 & R. apiculata & 5 & 0,050 & 5,882 & 0,200 & 15,152 & - & - & 21,034 \\
\hline 6 & T. catappa & 4 & 0,040 & 4,706 & 0,120 & 9,091 & - & - & 13,797 \\
\hline & Total & 85 & 0,850 & 100 & 1,320 & 100 & - & - & 200 \\
\hline \multicolumn{10}{|c|}{ Pancang } \\
\hline 1 & $X$. granatum & 41 & 0,066 & 45,833 & 0,280 & 20,000 & - & - & 65,833 \\
\hline 2 & A. marina & 34 & 0,054 & 37,500 & 0,600 & 42,857 & - & - & 80,357 \\
\hline 3 & S. alba & 8 & 0,013 & 9,028 & 0,240 & 17,143 & - & - & 26,171 \\
\hline 4 & R. apiculata & 5 & 0,008 & 5,556 & 0,200 & 14,286 & - & - & 19,842 \\
\hline 5 & T. catappa & 2 & 0,003 & 2,083 & 0,080 & 5,714 & - & - & 7,797 \\
\hline & Total & 90 & 0,1440 & 100 & 1,400 & 100 & - & - & 200 \\
\hline \multicolumn{10}{|c|}{ Tiang } \\
\hline 1 & A. marina & 34 & 0,014 & 36,842 & 0,560 & 33,333 & 6,474 & 21,448 & 91,623 \\
\hline 2 & S. alba & 28 & 0,011 & 28,947 & 0,600 & 35,714 & 7,635 & 25,295 & 89,956 \\
\hline 3 & $X$. granatum & 20 & 0,008 & 21,053 & 0,240 & 14,286 & 4,842 & 16,042 & 51,381 \\
\hline 4 & T. catappa & 9 & 0,004 & 10,526 & 0,160 & 9,524 & 7,759 & 25,706 & 45,756 \\
\hline 5 & R. apiculata & 3 & 0,001 & 2,632 & 0,120 & 7,143 & 3,474 & 11,509 & 21,284 \\
\hline & Total & 94 & 0,038 & 100 & 1,680 & 100 & 30,184 & 100 & 300 \\
\hline \multicolumn{10}{|c|}{ Pohon } \\
\hline 1 & A. marina & 57 & 0,0057 & 48,718 & 0,560 & 37,838 & 59,919 & 25,496 & 112,052 \\
\hline 2 & S. alba & 50 & 0,005 & 42,735 & 0,680 & 45,946 & 125,755 & 53,51 & 142,191 \\
\hline 3 & T. catappa & 5 & 0,0005 & 4,274 & 0,120 & 8,108 & 27,308 & 11,62 & 24,002 \\
\hline 4 & $X$. granatum & 5 & 0,0005 & 4,274 & 0,120 & 8,108 & 22,029 & 9,374 & 21,756 \\
\hline & Total & 117 & 0.0117 & 100 & 1,480 & 100 & 235,011 & 100 & 300 \\
\hline Kete & $\begin{aligned} & \text { ngan: } \mathrm{n} \\
& \mathrm{K} \\
& \mathrm{KR} \\
& \mathrm{F} \\
& \mathrm{FR} \\
& \mathrm{D} \\
& \mathrm{DR} \\
& \mathrm{INP}\end{aligned}$ & $\begin{array}{l}=\mathrm{Jur} \\
=\mathrm{Ke} \\
=\mathrm{Ke} \\
=\mathrm{Fre} \\
=\mathrm{Fre} \\
=\mathrm{Do} \\
=\mathrm{Do} \\
=\text { Ind }\end{array}$ & $\begin{array}{l}\text { lah Individu } \\
\text { apatan } \\
\text { apatan Relat } \\
\text { kuensi } \\
\text { kuensi Relat } \\
\text { ninansi } \\
\text { ninansi Rela } \\
\text { eks Nilai Pen }\end{array}$ & & & & & & \\
\hline
\end{tabular}

kategori pohon yaitu $S$. alba sebesar $53,51 \%$. Hal ini menunjukkan bahwa jenis $T$. catappa dan $S$. alba memiliki luasan populasi yang paling tinggi pada lokasi penelitian.

\section{KESIMPULAN}

Berdasarkan penelitian yang dilakukan, dapat diambil kesimpulan bahwa:

1. Keanekaragaman vegetasi mangrove di Pantai Tanamon termasuk dalam tingkat sedang dengan nilai indeks keanekaragaman Shannon-
Wienner sebesar 1,412 yang tersusun oleh 6 jenis mangrove yaitu Avicennia marina, Sonneratia alba, Xylocarpus granatum, Rhizophora apiculata, Nypa fruticans dan Terminalia catappa.

2. Indeks nilai penting tertinggi pada kategori semai yaitu sebesar 72,977 \% pada jenis Xylocarpus granatum, kategori pancang 80,357 \% pada Avicennia marina, kategori tiang $91,623 \%$ pada A. marina dan 
kategori pohon 142,191\% pada jenis Sonneratia alba.

\section{DAFTAR USTAKA}

Fachrul MF (2006) Metode sampling bioekologi. Bumi Aksara. Jakarta

Genisa AB (2006) Keanekaragaman fauna ikan di perairan mangrove Sungai Mahakam Kalimantan Timur. Oseanologi dan Limnologi 41(3): 39-53

Himmah I, Utami S, Baskoro K (2010) Struktur dan komposisi vegetasi habitat julang emas (Aceros undulates) di Gunung Ungaran Jawa Tengah. Jurnal Sains dan Matematika 18(1): 104-110

Istomo, Kusmana C (1997) Penuntun praktikum ekologi hutan. Laboratorium Ekologi Hutan Fakultas Kehutanan IPB. Bogor

Kaunang TD, Kimbal JD (2009) Komposisi dan struktur vegetasi hutan mangrove di Taman Nasional Bunaken Sulawesi Utara. Agritek 17(6): 1163-1171

Krebs CJ (1972) Ecology the experimental analysis of distribution and abundance. Harper and Row. New York Evanston San Fransisco London.

Noor YR, Khazali M, Suryadiputra INN (1999) Panduan pengenalan mangrove di Indonesia. PKA/WIIP. Bogor.
Nursal, Fauziah Y, Ismiati (2005) Struktur dan komposisi vegetasi mangrove Tanjung Sekodi Kabupaten Bengkalis Riau. Jurnal Biogenesis 2(1): 1-7

Onrizal, Simarmata S, Wahyuningsih H (2009) Keanekaragaman makrozoobenthos pada hutan mangrove yang direhabilitasi di Pantai Timur Sulawesi Utara. Natur Indonesia 11(2): 94-103

Romadhon A (2008). Kajian nilai ekologi melalui inventarisasi dan nilai indeks nilai penting (INP) mangrove terhadap perlindungan lingkungan Kepulauan Kangean. Embryo 5(1): 82-97

Simbala HEI (2007) Keanekaragaman floristik dan pemanfaatannya sebagai tumbuhan obat di Kawasan Konservasi II Taman Nasional Bogani Nani Wartabone (Kabupaten Bolaang Mongondow Sulawesi Utara). Disertasi. Sekolah Pascasarjana IPB. Bogor

Suzana B, Timban J, Kaunang R, Ahmad F (2011) Valuasi ekonomi sumberdaya hutan mangrove di Desa Pales Kecamatan Likupang Barat Kabupaten Minahasa Utara. ASE. 7(2): 29-38

Syah AF, Purwaningsih R (2007) Struktur ekosistem mangrove di Pesisir Utara Klampis Kabupaten Bangkalan. Embryo 4(1): 31-44 